\title{
UMA FLOR EM METAMORFOSE: A EXISTÊNCIA LÉSBICA EM MOMENTOS DE SER: OS ALFINETES DE SLATER NÃO TÊM PONTAS, DE VIRGINIA WOOLF
}

\author{
OLIVEIRA, Luísa Nunes Galvão Caron de ${ }^{1}$
}

\begin{abstract}
RESUMO: A fim de lançar luz a uma questão ainda pouco esmiuçada na ficção de Virginia Woolf, apresentamos, neste artigo, uma análise do conto "Momentos de ser: Os alfinetes de Slater não têm pontas" sob um duplo e indissociável viés: a violência simbólica, conforme explicitou Pierre Bourdieu, e a existência lésbica, no sentido proposto por Adrienne Rich. Pretendemos, ainda, através do estudo sobre ficções lébicas proposto por Laura Arnés, evidenciar como Woolf, ao ressignificar as relações entre corpo e texto, desestabiliza "a estrutura canônica do desejo" (2018, p. 174), abrindo para novas possibilidades de leitura e escrita.
\end{abstract}

PALAVRAS-CHAVE: Virginia Woolf, conto, ficção lésbica.

\section{A FLOWER IN TRANSFORMATION: LESBIAN EXISTENCE IN VIRGINIA WOOLF'S MOMENTS OF BEING: SLATER'S PINS} HAVE NO POINT

\begin{abstract}
In order to elucidate an unexplored question in the work of Virginia Woolf, this article analyses the short story "Moments of being: Slater's pins have no points" using as groundwork the concepts of Symbolic Violence, by Pierre Bourdieu and Lesbian Existence, by Adrienne Rich. It also intends, based on Laura Arné's study on lesbian fiction, to explain how Woolf creates new possibilities of reading and writing by reframing the relationship between body and text, destabilizing the "canonical structure of desire" (2018, p. 174).
\end{abstract}

KEYWORDS: Virginia Woolf, short story, lesbian fiction.

\footnotetext{
${ }^{1}$ Mestranda no Programa de Pós- Graduação em Estudos da Literatura na Universidade Federal Fluminense (UFF). Atualmente dedica-se integralmente à pesquisa, sendo bolsista CAPES. E-mail: luisacaron@ gmail.com Jangada | nr. 14, jul/dez, 2019 | ISSN 2317-4722 
A obra de Virginia Woolf (1882 - 1941) abriu as portas para uma crítica plural e muitas vezes controversa. Seus numerosos ensaios, romances e contos, após terem sido alvos de uma dura recepção por parte de seus coetâneos e analisados por uma crítica literária que atentava apenas aos aspectos formais do texto, são revistos pela teoria feminista somente a partir da década de 1970. Essa importante revisão epistemológica, no entanto, manteve oculto a princípio um traço relevante e, pode-se dizer, substancial de sua obra: a representação da lesbianidade.

Em 1996, uma coletânea que reúne ensaios e artigos intitulada Virginia Woolf: Lesbian Readings, é o primeiro livro dedicado ao reconhecimento da existência lésbica na vida e obra da autora inglesa. Na introdução, Eileen Barret recorda-nos a centralidade do papel das mulheres na ficção de Woolf e afirma que as experiências lésbicas vivenciadas por ela, explicitamente registradas em seus diários e cartas, ecoam na produção de seus textos ficcionais, ainda que biógrafos e críticos persistam em invisibilizar ou dirimir sua sexualidade reduzindo-a a simplificações freudianas que recorrem ao desejo de uma mãe ausente ${ }^{3}$.

Com o intuito de contribuir aos esforços empreendidos pela crítica que confere justa visibilidade a essa questão, pretendemos analisar neste artigo o conto "Momentos de ser: Os alfinetes de Slater não têm pontas" sob um duplo e indissociável viés: a violência simbólica, conforme explicitou Pierre Bourdieu, e a existência lésbica, no sentido proposto por Adrienne Rich. Por fim, pretendemos analisar como é retratada a lesbianidade através da chave de leitura proposta por Laura Arnés, para quem a representação da existência lésbica em um texto ficcional ressignifica uma tradição e abre para novas possibilidades textuais, tanto em relação ao conteúdo quanto à forma.

\footnotetext{
2 Disponível em: https://www.suplementopernambuco.com.br/in\%C3\%A9ditos/1854-safo-de-lesbos,-umpoema.html. Acesso em: 01/09/2019.

${ }^{3}$ Eileen Barret refere-se à recente biografia Virginia Woolf (1995), de James King, em que o autor, escrevendo sobre a relação amorosa de Virginia Woolf e Vita Sackville-West, afirma: "Vita wanted to become a male lover who would compete for and win her mother's embrace, whereas Virginia's desire was to be hugged and care for by a maternal woman" $(1996$, p. 6) - "Vita queria tornar-se uma amante masculina que competiria e conquistaria o abraço de sua mãe, enquanto o desejo de Virginia era ser abraçado e cuidado por uma mulher materna." - Trad. revisor.
}

Jangada | nr. 14, jul/dez, 2019 | ISSN 2317-4722 
O conto "Momentos de ser: os alfinetes de Slater não têm ponta", originalmente publicado pela revista Forum, de Nova Iorque, em 1928, hoje integra a antologia Uma casa assombrada, organizada postumamente pelo marido de Virginia, Leonard Woolf. Segundo Leonard afirma no prefácio da antologia ${ }^{4}$, o projeto dessa publicação teria sido discutido com a autora, que desejava reeditar Monday or Tuesday, seu até então único livro de contos. A versão presente em Uma casa assombrada, ainda que com poucas diferenças, não é a mesma que Virginia envia aos editores da revista. Sobre esta, temos o registro de uma carta da autora enviada a Vita Sackville-West, em julho de 1927: "Eu acabo de escrever, ou reescrever, uma breve história sobre safismo para os americanos" seu tema central é precisamente a relação homoerótica entre duas mulheres, a que Woolf chama de "safismo" em referência à poeta grega Safo de Lesbos, considerada a primeira escritora lésbica da história.

O conto apresenta duas personagens, Polly Kingston e Julia Craye, construídas, principalmente, a partir das impressões, divagações, recordações e ficcionalizações de uma terceira personagem, Fanny Wilmot. De fatos concretos sobre a vida de Fanny pouco sabemos ao findar do conto, já que seus pensamentos se dirigem principalmente à reconstrução da história de Miss Craye, sua professora de piano. Fanny nutre por ela um sentimento ambivalente de estranhamento e admiração, que se revelará, conforme veremos, como parte do processo de autoconhecimento da personagem.

Fazendo coro ao estilo literário de Woolf em que se combinam o adensamento no fluxo de consciência das personagens e a sobreposição temporal, "Os alfinetes de Slater não tem pontas" é um texto curto, mas estruturalmente complexo. Como o romance Rumo ao Farol, analisado por Erich Auerbach em seu célebre ensaio “A meia marrom”, o conto não traz apenas o monólogo interior de Fanny, mas intercala a voz de um narrador onisciente com os fluxos de consciência de Fanny e Polly. Segundo o crítico, esse processo, o qual denominou "representação pluripessoal da consciência" (2015, p. 483), tem a intenção de levar o leitor a aproximar-se de vários ângulos de uma mesma personagem. Assim, a autora busca "atingir a menor distância ao alcance das possibilidades humanas de conhecimento e expressão" (2015,

\footnotetext{
4 "Em 1940, finalmente, ela resolveu reunir esses contos em novo livro e nele incluir grande parte daqueles que anteriormente haviam aparecido em Monday or Tuesday, assim como os que ulteriormente foram publicados em revista e alguns inéditos" (WOOLF, 1984, p. 7)

${ }^{5}$ Trecho original: "I've just written, or rewritten a nice little story about Sapphism for the Americans." (WOOLF, 2003, p. 299)
}

Jangada | nr. 14, jul/dez, 2019 | ISSN 2317-4722 
p. 483) e o leitor pode compreender mais amplamente quem é Julia Craye ao ser exposto às perspectivas de Fanny, Polly e do narrador observador.

O tempo da narrativa, igualmente próprio ao estilo de Woolf em seus romances, se dá a partir do entrecruzamento do breve tempo presente da ação com a longa digressão interior das personagens. O tempo externo ocorre apenas no breve momento da pergunta de Miss Craye, seguida pela queda da flor e do alfinete, ao início do conto, e à recolha da flor e o beijo das duas personagens, nos parágrafos finais. Na realidade interior, a ordem cronológica deixa de ser regra, dando lugar a muitas camadas temporais que se sobrepõem. Segundo esclarece-nos a leitura de Auerbach:

No caso de Virginia Woolf, os acontecimentos exteriores perderam por completo o seu domínio; servem para deslanchar e interpretar os interiores, enquanto que, anteriormente e em muitos casos ainda hoje, os movimentos internos serviam preponderantemente para a preparação e a fundamentação dos acontecimentos exteriores importantes. Também isto vem à luz no acaso e na causalidade do motivo externo, que desencadeia o processo interno, muito mais importante. (AUERBACH, 2015, p. 485)

No caso desse conto veremos que o processo interno, ocasionado pela queda banal de um alfinte, além de nos aproximar da vida íntima das personagens, dará ensejo a uma visão crítica da sociedade inglesa do início do século XX.

A pergunta que Miss Craye dirige à Fanny Wilmot na primeira linha do conto " - Os alfinetes de Slater não tem ponta, você já reparou nisso?” servirá de leitmotif ao texto. A partir dela Fanny começa a se questionar sobre quem é essa misteriosa mulher, pois, vestindo-se sempre do mesmo modo "como um besouro compactado no seu élitro, azul no inverno, verde no verão", como se vivesse "no mundo frio e vítreo das fugas de Bach" (1984, p.125), ela nada deveria saber sobre alfinetes. Com essa primeira caracterização da professora, podemos já perceber o estranhamento e a curiosidade que ela provoca em sua aluna.

Ainda no segundo parágrafo, a memória de Fanny conduz-nos à voz de Miss Kingston, diretora do Conservatório onde trabalha Miss Craye. A partir da alusão à morte do irmão de Julia, Miss Kingston descreve os estranhos hábitos da família Craye. Em seu relato, ressaltamse dois aspectos importantes. Primeiro, a condição social da família, evidentemente abastada pela descrição dos móveis e objetos que possuíam. Segundo, o fato de que nenhum dos Craye se casara. Isso é anunciado a princípio como uma espécie de maldição, o que leva Fanny a 
imaginar que a causa de Miss Craye ter conhecimento sobre alfinetes seria uma tentativa de quebrar esse infortúnio que os distanciava do mundo. Em seguida, imagina como seria Polly na infância, a correr pela casa, e descreve o olhar de Julius observando-a à distância: "olhou-a com o olhar da irmã, aquele olhar insistente e arrebatador.” (1984, p. 127). Este olhar, carregado de uma distância insondável, de uma necessidade premente de atingir o objeto amado, mas sendo impedido de o possuir é, para Fanny, fruto da maldição que se abate sobre os Craye, a qual Julia tentava quebrar ao executar a fuga de Bach para agradar suas alunas. Nesse instante, Fanny revela ter consciência de ser a aluna predileta de Miss Craye e, em seguida, repete-se o leitmotif do texto: "Os alfinetes de Slater não tinham pontas." (1984, p. 127).

Enquanto ainda divaga sobre o olhar da professora, Miss Craye recolhe a flor que caíra. Fanny lembra-se, então, de alguns comentários depreciativos de Julia a respeito dos homens e imagina, agora com mais proximidade, cenas que poderiam ter ocorrido em sua juventude. Divaga sobre as viagens que sua professora teria feito sozinha e os pedidos de casamento que teria recusado. Assim, sua resistência em se casar deixa de ser considerada uma maldição para tornar-se símbolo de sua independência. Quando Fanny finalmente recolhe o alfinete, o tempo da narrativa torna-se ainda mais obscuro e, através dos olhos de Miss Craye, ela pode ver "o passado mais remoto através do mais remoto passado" (1984, p. 133). Fanny vê Julia abrir os braços e as duas, enfim, se beijam. O desenlace do conto, no entanto, deixa em suspenso esse fato: elas realmente se beijam ou ainda estamos observando os devaneios de Fanny?

Antes de arriscar uma resposta a essa questão, é relevante considerarmos o tempo histórico de Virginia Woolf e como se configura a sociedade retratada no conto, a fim de estendermos para a contemporaneidade algumas das problemáticas traçadas pela autora. Sabemos, a partir de seus textos ensaísticos, tais como o longo ensaio Um teto todo seu e os artigos reunidos no livro Profissões para mulheres e outros artigos feministas, que a sociedade inglesa dos fins do século XIX e início do século XX permitia pouquíssima liberdade às mulheres. Esses dois livros, na realidade, compilam relatos da autora em conferências realizadas por mulheres, num período em que elas começam a ingressar na vida pública e a lutar por seus direitos de voto. Em seus discursos, Woolf compartilha as dificuldades as quais tinha de enfrentar cotidianamente como uma mulher escritora.

Em $O$ teto todo seu, a autora sugere que sem o próprio dinheiro e um aposento em que pudesse estar só, era muito difícil para uma mulher exercer o ofício da escrita. Dentre as questões que levanta, vemos as diferenças entre homens e mulheres em relação ao ingresso nas 
universidades e ao acesso às bibliotecas, por exemplo, locais onde somente era permitida a entrada àquelas acompanhadas ou autorizadas por um homem. Vemos, ademais, a diferença no número de livros publicados por homens e mulheres, sendo escassos os livros escritos por mulheres, principalmente no que se refere à poesia e assuntos científicos em geral.

Essas questões de ordem material expostas por Woolf em seus ensaios aparecem também em "Os alfinetes de Slater não têm ponta". Podemos constatar, por exemplo, que só é possível à Miss Craye exercer o seu ofício livremente e não se casar, graças a sua condição social. Além disso, Woolf comprova sua teoria de Um teto todo seu, já que Julia pode viver no mundo das "fugas de Bach" justamente por ter uma profissão que a sustenta e uma casa só para si.

No entanto, a dominação masculina não se dá apenas no estrato econômico. Como demonstra Pierre Bourdieu, as ordens materiais e simbólicas se fundem na consolidação dessa relação de dominação sendo, diversas vezes, difícil de enxergá-la graças a seu longo processo histórico de naturalização.

A divisão entre os sexos parece estar "na ordem das coisas", como se diz por vezes para falar do que é normal, natural, a ponto de ser inevitável: ela está presente, ao mesmo tempo, em estado objetivado nas coisas (na casa, por exemplo, cujas partes são todas "sexuadas"), em todo o mundo social e, em estado incorporado, nos corpos e nos habitus dos agentes, funcionando como sistemas de esquemas de percepção, de pensamento e de ação. (BOURDIEU, 2010, p. 17)

Para a consolidação de sua teoria acerca da dominação masculina, Bourdieu recorre muitas vezes à Virginia Woolf, tecendo comentários a respeito da acuidade de sua escrita. O conceito de dominação masculina, criado por Bourdieu para explicar o mecanismo de naturalização do processo histórico de submissão da mulher ao homem, é exemplo da violência simbólica. Esta, por sua vez, denotando a violência invisível que se constrói sob um paradoxal contrato entre dominante e dominado, tem como fonte a expressão "poder hipnótico da dominação" (BOURDIEU, 2010, p. 8) criada por Woolf.

Em determinada passagem, Bourdieu analisa, assim como Auerbach, um trecho do romance Rumo ao farol. A partir da leitura de Bourdieu, é possível perceber que Woolf trabalha em seus textos ensaísticos os problemas materiais pelos quais são subjugadas as mulheres na sociedade patriarcal, enquanto em seus romances e contos indica diversas situações nas quais Jangada | nr. 14, jul/dez, 2019 | ISSN 2317-4722 
as mulheres passam por violência simbólica devido à consolidação da visão androcêntrica no mundo ocidental. Estas, muitas vezes são expressas por Woolf através da ironia e/ou do uso de símbolos e metáforas e, por isso, não são necessariamente compreendidas de imediato por todos os seus leitores. Vemos, por exemplo, a diferença entre Julia Craye e seu irmão Julius. No conto, Julius aparece como um duplo de sua irmã, a começar pela similaridade do nome. O comportamento estranho e frio também é uma característica que os une e, por isso, todas as vezes que Fanny recorda de Julius através da memória de Polly, compreende melhor quem é Julia. Entretanto, ao contrário da irmã, que vivia isolada no mundo privado, Julius carrega consigo o epíteto "o famoso arqueólogo".

Sabemos que Julius frequentou a faculdade, pois seus amigos de Oxford e Cambridge eram atraídos pela beleza de Julia. Ademais, Julius "evidentemente, era um homem bastante conhecido" (1984, p. 126), segundo Miss Kingston, ou seja, uma figura pública. Os dois irmãos evidenciam uma estrutura que, como recorda-nos ainda Bourdieu, "funciona como uma imensa máquina simbólica que tende a ratificar a dominação masculina sobre a qual se alicerça" (2010, p. 18), opondo o espaço público aos homens e o espaço privado às mulheres. Ainda segundo o sociólogo, essa estrutura social, baseada nessa estrita divisão, constrói o corpo dos indivíduos. Julia se comporta como deve ser comportar uma mulher, encerrada em seus vestidos, fechada como um "besouro em seu élitro" (1984, p. 125). Contudo, não reage ao mundo como um corpo subserviente, pronto para cumprir suas funções de esposa e mãe e, por isso, sofre as consequências do isolamento e da incompreensão.

Evidentemente, mas, quem sabe, estupidamente, sentiam-se apiedados dela por uma coisa pela qual ela jamais pedira piedade (com efeito, era por costume reticente, só falando sobre seu estado de saúde como um guerreiro falaria de seu adversário) - sentiam-se apiedados dela por fazer sempre tudo sozinha. (WOOLF, 1984, p. 132-133)

Como Julia Craye, as mulheres que rejeitavam seu papel social eram encaradas como seres incompletos e, nessa lógica, dignas de pena. Adrienne Rich, no ensaio intitulado "Heterossexualidade compulsória e resistência lésbica", reitera a ideia de dominação masculina de Bourdieu para explicitar essa questão, acrescentando a problemática da sexualidade.

Na tradição das ciências sociais, afirma-se que o amor primário entre os sexos é "normal", que as mulheres precisam dos homens como seus protetores sociais e econômicos, para a sexualidade adulta e para a complexão 
psicológica ou, então, que a família constituída heterossexualmente seria a unidade social básica, que as mulheres que não estão ligadas, em sua intensidade primária, aos homens devem ser, em termos funcionais, condenadas a uma devastadora marginalidade, muito maior que a de ser mulher. (RICH, 2010, p. 41)

A violência simbólica, como retratada neste conto, pode passar despercebida em alguns aspectos se não atentarmos que a narrativa de Woolf, além de escancarar como as estruturas históricas da ordem masculina afetam a vida das mulheres, coloca em questão o modo como afetam e invisibilizam as sexualidades não-hegemônicas.

No artigo "The point of 'Slater's Pins': Misrecognition and the Narrative Closet", Susan Clements chama a atenção para os raríssimos livros que traziam narrativas lésbicas na época de Woolf. Aqueles que tentavam se aproximar da realidade na descrição dos amores lésbicos, isto é, não impondo-lhes padrões heteronormativos, eram censurados. Desse modo, Virginia Woolf sagazmente utiliza-se de metáforas socialmente aceitas para subvertê-las dentro do próprio argumento da narrativa.

Carefully transcribed into heterosexual terms, "Slater's Pins Have No Points" makes uses of socially acceptable metaphors only to resist and subvert them from within de story itself. Woolf accomplishes this subversion through a covert reflection on the very practice of heterosexual coding: on its concious use as an escape from censorship and its unconscious use as an escape from self. (CLEMENTS, 1994, p. 16)

A partir do conceito de "misrecognition", criado por Louis Althusser, Clements interpreta a construção da personagem Fanny Wilmot. Para o teórico marxista, "misrecognition" explicita o mecanismo social que impõe a necessidade de assumirmos uma identidade particular a fim de nos constituírmos como sujeitos. Essas identidades preestabelecidas obscurecem a percepção de outros desejos e formas de ser no mundo ${ }^{7}$. Fanny,

\footnotetext{
${ }^{6}$ Cuidadosamente transcrito para o linguajar heterossexual, "Os alfinetes de Slater não têm pontas" utiliza-se de metáforas socialmente aceitáveis, apenas para resistir e subvertê-las dentro da própria história. Essa subversão é realizada por Woolf através de uma reflexão encoberta pelos códigos heterossexuais: usando-os conscientemente para escapar da censura e, inconscientemente, para escapar de si.

7 "Ideology "acts" or "functions" in such a way that it... "transforms' the individuals into subjects... by that very precise operation I have called Interpellation or hailing...By this...he becomes a subject. Why? Because he has recognized that the hail was 'really' addressed to him, and that 'it was really him who was hailed"' (ALTHUSSER in CLEMENTS, 2010, p. 22.) - "A ideologia "age" ou "funciona" de tal maneira que ... 'transforma' os indivíduos Jangada | nr. 14, jul/dez, 2019 | ISSN 2317-4722 113 | P á g i n a
} 
nesse sentido, obrigada a assumir a única identidade que lhe cabia - mulher e heterossexual não reconhece que pode sentir atração por outras mulheres e tampouco compreende sua professora como uma mulher lésbica. Virginia Woolf vai desmascarando, ao longo da narrativa, os obstáculos socialmente impostos ao reconhecimento da orientação sexual da personagem.

No início do conto, Fanny não consegue conceber a atração pela professora e, por isso, desvia sua atenção para Julius, reconstruindo imaginariamente o passado dessa figura que não conheceu antes mesmo de devanear sobre o passado de Julia. Apesar de perceber que o olhar de Julius é como o da irmã, "insistente e arrebatador" (1984, p. 127), Fanny não reflete sobre o desejo que a professora lhe provoca, em vez disso, coloca palavras românticas na boca de Julius: “- Estrelas, sol, lua - o olhar parecia dizer - margaridas na relva, fogueira, geada na vidraça, meu coração é todo seu." (1984, p. 127).

Adrienne Rich defende que a heterossexualidade não é uma questão de "escolha" ou "preferência", mas uma instituição intimamente ligada à manutenção do patriarcado. Para que este se mantenha e manifeste, é necessário que aquela seja constantemente reiterada no imaginário feminino. A arte, a literatura e o cinema, por exemplo, são utilizados como mecanismos que reforçam a idealização do amor romântico heterossexual.

Na tradição Ocidental, uma camada - a romântica - assegura que as mulheres se voltem, inevitavelmente, mesmo que impetuosa e tragicamente, para os homens. Até mesmo quando a atração é suicida (por exemplo, em Tristão e Isolda; em The Awakening, de Kate Chopin), ela é um imperativo orgânico. (RICH, 2010, p. 41)

Assim, as palavras apaixonadas que Fanny imagina serem ditas pelo irmão de Julia, poderiam ter sido proferidas por sua professora. Mas como imaginar versos de amor de uma mulher para outra, numa sociedade em que o amor romântico é idealizado e que, além disso, pouquíssimas escrevem poesia?

Quando Fanny imagina a cena em que Julia recusa-se a ouvir as lisonjas do amigo, percebemos, novamente, que ela não é capaz de conceber a homossexualidade de Julia. Primeiro, essa recusa é encarada como uma maldição familiar. Em seguida, quando se lembra

em sujeitos ... por essa operação muito precisa que chamei Interpelação ou saudação ... Por isso ... ele se torna um sujeito . Por quê? Porque ele reconheceu que a saudação foi 'realmente' endereçada a ele e que 'foi realmente ele quem foi saudado" - Trad. do revisor

Jangada | nr. 14, jul/dez, 2019 | ISSN 2317-4722

114 | P á g i n a 
do comentário de Julia: "Sem dúvida os homens servem para nos proteger” (1984, p. 128), Fanny entende que a razão estaria vinculada unicamente ao seu desejo por independência.

A respeito do comentário de Julia Craye, nota-se, por alguns motivos, que ele é evidentemente irônico. Primeiro, pelo "sorriso estranho" (1984, p. 128) que acompanha sua fala. Depois, porque ela, tendo recusado essa que seria “a única serventia dos homens" (1984, p. 129), mostra ter consciência de que não é natural às mulheres a necessidade de serem protegidas por eles. Sua razão é de ordem muito mais material, pois "a aula estendera-se mais que o habitual e escurecera" (1984, p. 128), o que evidencia o perigo de uma mulher andar à noite desacompanhada. Um pouco depois, quando uma aluna tem de sair apressada para não desencontrar-se do marido, Julia revela mais uma vez, "rindo com crueldade", o que pensa a respeito dos homens: "São todos uns ogros" (1984, p. 131).

É possível comparar a situação da escritora lésbica, ou seja, da própria Virginia Woolf, com a situação de Julia Craye. Como Julia ao tentar se libertar da dominação masculina não podia deixar de reconhecer que "os homens servem para nos proteger", Woolf também se via nesse entre-lugar, pois exercia uma escrita de enfrentamento, reconhecendo, entretanto, a necessidade de aprovação masculina para não cair na censura ou esquecimento.

Em outro ensaio de Adrienne Rich, "Quando da morte acordamos: a escrita como revisão", a poeta, refletindo sobre o tom da linguagem de Woolf em Um teto todo seu, percebe que ela está determinada o tempo todo a "não parecer zangada", pois, mesmo falando para mulheres, tem consciência de que os homens a escutavam e precisava deles para que seus textos fossem aceitos, já que uma linguagem "sem paixão" era "a atitude que os homens cultos achavam que o escritor deveria cultivar" (2017, p. 69). Na leitura de Rich, o controle do juízo de gosto masculino causa problemas para as mulheres escritoras, pois estas deveriam ser livres para exprimir sua raiva e suas paixões a fim de conseguirem encontrar quem são verdadeiramente.

Sem dúvida, a crítica da autora é de suma importância. No entanto, preferimos reconhecer, com base nos apontamentos de Laura Arnés e ainda na linha de raciocínio proposta por Susan Clements, a potencialidade que esse entre-lugar proporcionou à escrita de Virginia Woolf.

Em seu livro Ficciones lesbianas: literatura y afectos em la cultura argentina, Laura Arnés procura definir as noções de ficções lésbicas argentinas. Apesar do recorte de sua pesquisa não ser de nosso interesse nesse momento, o primeiro capítulo do livro, publicado em 
formato de artigo para a revista Criação \& Crítica, traz reflexões que nos ajudam a pensar as ficções lésbicas de forma plural e este conto de Woolf, em particular.

Arnés inicia seu texto apontando para o problema da falta de visibilidade crítica às ficções lésbicas. O mesmo problema foi marcado por Adrienne Rich - ainda que não referindose especificamente à crítica, mas à cultura no geral - quando reconheceu essa política de invisibilização como um dos instrumentos de manutenção da heterossexualidade compulsória.

A existência lésbica tem sido vivida (diferentemente, digamos, da existência judaica e católica) sem acesso a qualquer conhecimento de tradição, continuidade e esteio social. A destruição de registros, memória e cartas documentando as realidades da existência lésbica deve ser tomada seriamente como um meio de manter a heterossexualidade compulsória para as mulheres (...) $(\mathrm{RICH}, 2010$, p. 41)

Para Arnés, que entende a categoria lésbica como diferença e, portanto, como possibilidade de "desestabilizar a estrutura canônica do desejo" (2018, p. 174) a falta do nome ou o segredo podem ser estratégicos.

Sabemos que lesbianismo e campo de visão mantiveram, historicamente, uma relação conflitiva. É habitual que a falta (que pode tomar diversas formas: o segredo, o hiato, o desvio, o disfarce...) atribua ao lesbianismo sua forma e sua condição de acesso à representação. Contudo, acredito que é possível ler essa invisibilidade em termos de estratégia de representação. (ARNÈS, 2018, p. 171)

Essa estratégia, no caso do conto de Virginia Woolf, se realiza através da utilização de uma linguagem poética para expressar o encontro erótico entre as personagens Fanny e Julia, linguagem que transborda "as identidades reconhecíveis, delineando outros corpos/textos ou outras relações entre os corpos e os textos possíveis" (ARNÉS, 2018, p. 173). Isso significa que mesmo sem expressar as palavras "lésbica" ou "safismo" no conto, a autora evoca, para além do beijo, uma miríade de símbolos com os quais vai construindo a intensidade do encontro entre as personagens. O primeiro deles, o alfinete sem ponta, parece indicar, como o faz tanto a leitura de Susan Clements, quanto de Annete Oxindine no artigo "Sexing the epiphany in 'Moments of being' Woolf's nice little story about sapphism", um trocadilho (pin/penis) para indicar a 
inutilidade do falo. Por isso a frase é repetida na abertura e fechamento do conto, quando, após o beijo das duas personagens, Julia transforma a pergunta em uma afirmação.

Como seu irmão, Julia de início não consegue possuir o que quer, e transforma, na perspectiva de Fanny, esse objeto de desejo em beleza abstrata e inatingível.

E era desse jeito que Julia também olhava, meio virada no banco do piano, sorrindo. Está no campo, está na vidraça, está no firmamemnto - a beleza; e não consigo alcançá-la, não consigo possuí-la - eu, parecia querer acrescentar, fechando a mão de uma maneira muito peculiar, que a cultuo com tanta paixão, daria o mundo inteiro para possuí-la! (WOOLF, 1984, p. 128)

Entretanto, logo após à descrição dessa angústia, apanha no chão a flor que caíra, presa pelo alfinete no peito de Fanny. Esta, que antes era uma rosa - símbolo da sexualidade feminina - metamorfoseia-se num cravo. Segundo Janet Winston, que propõe uma análise comparativa deste conto de Woolf com o conto "Carnation" de Katherine Mansfield, cujo tema também é a relação amorosa homossexual, o cravo etimologicamente leva-nos ao sentido de "carne":

Underscoring the emblematic eroticism in Woolf's descriptions, the carnation itself (according to the Oxford English Dictionary) is tied to several (obsolete) meanings and etymological forms - "the colour of human flesh," "incarnation," and "coronation" - which suggest carnality, embodiment, and ritual. (WINSTON In BARRET, 1997, p.73) ${ }^{8}$

Com o cravo em mãos, a descrição que se segue é carregada de erotismo:

Ela comprimiu-o, Fanny sentiu, voluptuosamente na concha das mãos delicadas e de veias aparentes, cravadas de anéis de pérola incrustada e de cores esmaecidas. A pressão de seus dedos como que intensificava tudo o que havia de mais luminoso na flor, realçava-a; tornava-a mais folhosa, fresca, imaculada. (WOOLF, 1984, p. 128)

O movimento de seus dedos e o deleite que experimenta ao apertar a flor, realçandoa, sugere uma cena erótica entre duas mulheres. Contudo, mesmo nesse profundo contato com a flor, a professora ainda não consegue alcançar o que deseja, "pressionava-o; mas não o

\footnotetext{
${ }^{8}$ Acentuando o emblemático erotismo nas descrições de Woolf, "carnation" (cravo) (de acordo com o dicionário Oxford de inglês) está atado a muitos significados e formas etimológicas (obsoletas) - "a cor da carne humana", "encarnação" e "coroação" - que sugerem carnalidade, materialidade e ritual. (Tradução minha)
} 
possuía; não extraía prazer dele, não inteira e completamente" (1984, p. 128), pois não se trata ainda de um contato humano.

Enquanto refletia sobre a solidão de Miss Craye, Fanny encontra o alfinete. Nesse momento, olha para Julia e percebe que, ao contrário do que comentavam as pessoas que por ela sentiam pena, Julia "era uma mulher inabalavelmente feliz, venturosamente feliz, mesmo que por apenas aquele momento" (1984, p. 133). Fanny percebe que Miss Craye, segurando a prumo o cravo, vive um momento de êxtase. Em seguida, é a própria Fanny quem parece passar pela experiência de sair de si, ou melhor, de enfim se encontrar: "Por um momento tudo transparecia aos olhos de Fanny Wilmot, como se, ao olhar através de Miss Craye, visse a própria fonte do seu ser lançando gotas de pura prata.” (1984, p. 133). A partir daí, todos os tempos parecem se sobrepor num único instante em que Fanny enxerga diversos fragmentos esparsos da vida de Julia. Ela vê "o passado mais remoto através do mais remoto do seu passado." (1984, p. 133).

Segundo Laura Arnés, as paixões lésbicas na ficção inscrevem uma temporalidade que permite "escapar ao cronológico, imprimir outras realidades para se mover com e através do tempo, para encontrar passados e especular futuros e, no exato ponto em que os tempos se tocam, descobrir sentidos (de) presentes" (2018, p. 170). Desse modo, a constante busca de Julia se revela para Fanny no momento em que o tempo ordinário é suspenso e ela pode se abrir, enfim, à descoberta de novos sentidos.

Ela viu Julia.

Julia resplandeceu. Julia iluminou-se. Saída da noite, ela ardia como uma estrela branca e morta. Julia abriu os braços. Julia beijou-a nos lábios. Julia alcançou a posse.

- Os alfinetes de Slater não têm ponta - Miss Craye disse, rindo misteriosamente e soltando os braços, enquanto Fanny Wilmot, com os dedos trêmulos, prendia a flor no peito. (WOOLF, 1984, p. 134)

No versão original do conto, Woolf escolhe deixar ambíguo o desenlace final repetindo o verbo "ver". "She saw Julia - She saw Julia open her arms; saw her blaze; saw her kindle."” (2003, p. 214). Assim, não sabemos se Julia de fato a beija, ou se estamos diante de uma visão sonhadora de Fanny. De qualquer modo, sendo o beijo verdadeiro ou não, o fato é que nesse

\footnotetext{
${ }^{9}$ Ela vê Julia - Ela vê Julia abrir seus braços; vê seu esplendor; vê seu brilho. (Tradução minha) 
momento a epifania do conto se revela quando Fanny compreende a orientação sexual de sua professora e, afinal, tem uma revelação sobre sua própria sexualidade.

Nesse breve conto, vemos que Virginia Woolf tece não apenas uma crítica à sociedade de sua época, mas dá início a uma nova tradição que, antes dela, havia sido completamente obliterada. Atenta à potencialidade do texto ficcional, como afirma em Rumo ao farol, "I prefer where truth is important, to write fiction"10, a autora inglesa parece perceber, como Foucault, que "toda verdade é uma ficção efetiva” (ARNÉS, 2018, p. 175).

Assim, questionando os códigos culturais, enfrentando e ressignificando as ficções que nos são impostas como verdade, as ficções lésbicas são capazes de evidenciar novas formas de existir no mundo. Uma dessas formas foi exposta no conto de Woolf, autora que abriu as porta para que outras escritoras hoje possam exprimir a existência lésbica que, como afirmou Adrienne Rich, é “nossa criação contínua do significado dessa mesma existência.” (2010, p. 35).

\section{REFERÊNCIAS BIBLIOGRÁFICAS}

ARNÉS, L. "Ficções lésbicas: pontos de vista e contingências." Revista Criação e Crítica, USP, n²0 - Dossiê Sáfico, 2018.

AUERBACH, E. “A meia marrom” In. Mimesis: a representação da realidade na literatura ocidental. São Paulo: Perspectiva, 2015.

BARRET, E. Virginia Woolf: Lesbian Readings. Edited by Eileen Barret and Patricia Cramer. New York and London: New York University Press, 1997.

BOURDIEU, P. A dominação masculina. 9aed. Rio de Janeiro: Bertrand Brasil, 2010.

CLEMENTS, S. "The Point of "Slater's Pins": Misrecognition and the Narrative Closet". Tulsa Studies in Women's Literature. Vol. 13, No. 1 (Spring, 1994), pp. 15-26.

OXINDINE, A. 'Sexing the epiphany in 'Moments of being', Woolf's nice little story about sapphism”. Journal of the Short Story in English, 31, 1998. Disponível em:

https://journals.openedition.org/jsse/160. Acesso em: 01/09/2019.

RICH, A. "Heterossexualidade compulsória e existência lésbica." Tradução de Carlos Guilherme do Valle. Revista Bagoas, n. 5, 2010, p. 17-44.

RICH, A. "Quando da morte acordamos: a escrita como re-visão" In. BRANDÃO, I. Traduções da Cultura: Perspectivas críticas feministas (1970-2010). Florianópolis: Ed. UFSC, 2017.

WOOLF, V. A Haunted house: The complete shorter fiction. Edited by Susan Dick. London: Vintage, 2003.

. "Momentos de ser: Os alfintes de Slater não tem ponta" In. Uma casa assombrada/ contos. Rio de Janeiro: Nova Fronteira, 1984.

10 "Eu prefiro, quando a verdade importa, escrever ficção". Essa frase de Woolf encontra-se em nota de rodapé no livro Dominação Masculina, de Pierre Bourdieu. (2010, p. 86)

Jangada | nr. 14, jul/dez, 2019 | ISSN 2317-4722

119 | Pá g i na 
. Um teto todo seu. São Paulo: Tordesilhas, 2014.

2012.

. Profissões para mulheres e outros artigos feministas. São Paulo: L\&PM Pocket,

Jangada | nr. 14, jul/dez, 2019 | ISSN 2317-4722

120 | P á g i n a 